\title{
Percentage of Adults Aged $\geq 60$ Years Who Ever Had the Shingles Vaccine,* by Sex — National Health Interview Survey, 2008-2016 ${ }^{\dagger}$
}

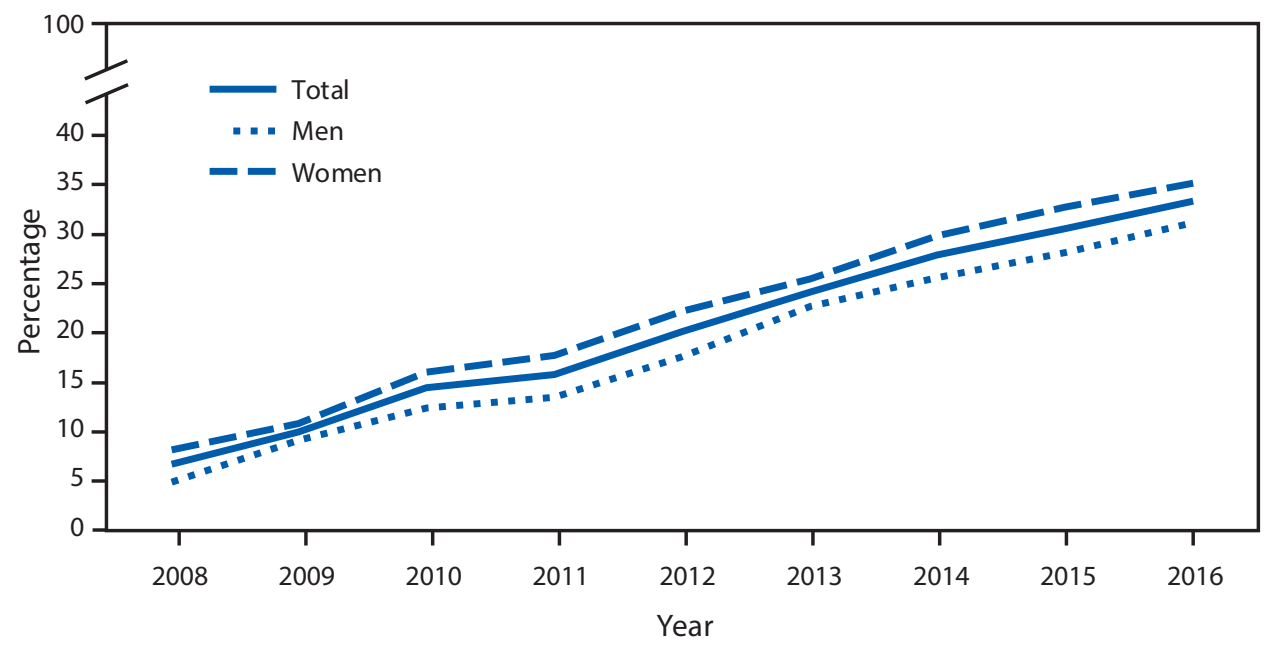

\footnotetext{
* Based on responses to the question "Have you ever had the zoster (ZOSS-ter) or shingles vaccine, also called Zostavax?"

† Estimates are based on household interviews of a sample of the noninstitutionalized U.S. civilian population and are derived from the National Health Interview Survey Sample Adult component.
}

The percentage of adults aged $\geq 60$ years who ever had the shingles vaccine increased from $6.7 \%$ in 2008 to $33.4 \%$ in 2016 . The percentage of men who had the vaccine increased from $4.9 \%$ to $31.2 \%$, and the percentage of women who had the vaccine increased from $8.2 \%$ to $35.2 \%$. For each year during $2008-2016$, women were more likely than men to have had the shingles vaccine.

Source: National Center for Health Statistics. National Health Interview Survey, 2008-2016. https://www.cdc.gov/nchs/nhis.htm.

Reported by: Mary Ann Bush, MS, mbush@cdc.gov, 301-458-4130; Anita L. Powell. 